\title{
Orderly Power Utilization System Modeling and Simulation
}

\author{
Yuejia Sun $^{\mathrm{a}}{ }^{*}$, Xiaojun Wang ${ }^{\mathrm{b}}$ and Sheng $\mathrm{Bi}^{\mathrm{c}}$ \\ School of Electrical Engineering, Beijing Jiaotong University, Beijing100044, China

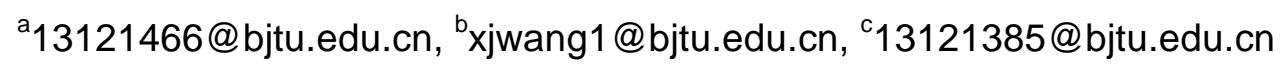

Keywords: system modeling; orderly power utilization; peak load shifting; typical daily load

Abstract. In order to solve the problem that the decision-making department's orderly power utilization plan is less elaborate, a model based on users' typical daily load curve is presented. The model can coordinate a variety of orderly power utilization means, and targets at power company' lowest economy cost while maintaining grid reliability. A number of large users' typical daily load curves in one region are used in the example. The genetic algorithm is also used as optimization tool to carry out simulation for aforesaid model. Analysis results show that the model can effectively reduce the orderly power utilization' economy cost for power company.

\section{Introduction}

China remains at the stage of relying on heavy chemical industry, so the demand for electrical energy is strong and seasonal power shortages persist in some areas [1]. Orderly power utilization refers to controlling portion of electricity demand, and maintaining stable electricity supply by means of administrative measures, economic instruments and technical methods, etc. [2]. Currently, orderly power utilization is limited to operational procedures, but lack provisions for the implementation details. Therefore, such procedures have been implemented in a less elaborate manner [3]. In order to solve existing problems, a decision-making model is firstly constructed based on load forecasting results of grid system as well as large users' typical daily load curves in one region. A number of orderly power utilization means are integrated to carry out a study on the peak shifting effect and economic cost of power companies in conducting orderly power utilization plan.

\section{Establishment of Orderly Power Utilization Model}

Objective Function. The objective function of orderly power utilization is expressed as follows:

$$
\begin{aligned}
& \min \left(\sum_{i=1}^{7} \sum_{j=1}^{24} X_{i, j}+\lambda Y\right) . \\
& X=\frac{X_{7 \times 24}^{\prime}+\left|X_{7 \times 24}^{\prime}\right|}{2} . \\
& X_{7 \times 24}^{\prime}=R_{7 \times 24}-S_{7 \times 24}+T_{7 \times 24} .
\end{aligned}
$$

Where $X$ is load gap matrix; $X_{i, j}$ is the load gap value at $j$ hour of $i$ day in the week of orderly power utilization preplan, the greater the value is, the lower the power grid reliability shows; $Y$ is economy cost of power companies; $\lambda$ is weight coefficient, it is used to adjust the relationship between the grid reliability and economic cost to get different orderly power utilization plans; $X_{7 \times 24}^{\prime}$ is intermediate variable; $R_{7 \times 24}$ is load forecasting matrix of the grid; $S_{7 \times 24}$ is the ceiling matrix of grid ideal operating range; $T_{7 \times 24}$ is load correction matrix.

Participation Means and Grading. Means and grading of users' participation in orderly power utilization are shown in Table 1. Each large user is limited to one orderly power utilization mean in a preplan week. 
Table 1. Users' participation means and grading

\begin{tabular}{|c|c|c|c|c|c|}
\hline Mean & $\begin{array}{l}\text { Gra- } \\
\text { ding }\end{array}$ & Concrete Measure & Mean & $\begin{array}{l}\text { Gra- } \\
\text { ding }\end{array}$ & Concrete Measure \\
\hline \multirow{2}{*}{$\begin{array}{c}\text { Peak } \\
\text { shifting } \\
\text { to valley }\end{array}$} & \multirow{2}{*}{1} & \multirow{2}{*}{$\begin{array}{l}\text { Transfer four hours' work plan at peak } \\
\text { time to valley time }\end{array}$} & \multirow{6}{*}{$\begin{array}{c}\text { Weekly } \\
\text { peak } \\
\text { shifting }\end{array}$} & 1 & $\begin{array}{c}\text { Alternate holiday on Monday and Tuesday, and } \\
\text { workday on Saturday and Sunday }\end{array}$ \\
\hline & & & & 2 & $\begin{array}{l}\text { Alternate holiday on Tuesday and Wednesday, and } \\
\text { workday on Saturday and Sunday }\end{array}$ \\
\hline \multirow{6}{*}{$\begin{array}{c}\text { Daily } \\
\text { peak } \\
\text { shifting }\end{array}$} & 1 & Put work time two hours ahead & & 3 & $\begin{array}{l}\text { Alternate holiday on Wednesday and Thursday, and } \\
\text { workday on Saturday and Sunday }\end{array}$ \\
\hline & 2 & Put work time one hour ahead & & 4 & $\begin{array}{c}\text { Alternate holiday on Thursday and Friday, and } \\
\text { workday on Saturday and Sunday }\end{array}$ \\
\hline & 3 & Put work time one hour later & & 5 & Alternate holiday on Friday, and workday on Sunday \\
\hline & 4 & Put work time two hours later & & 6 & $\begin{array}{l}\text { Alternate holiday on Monday and workday on } \\
\text { Saturday }\end{array}$ \\
\hline & 5 & Put work time three hours later & \multirow{5}{*}{$\begin{array}{c}\text { Weekly } \\
\text { peak } \\
\text { averting }\end{array}$} & 1 & Monday close \\
\hline & 6 & Put work time four hours later & & 2 & Tuesday close \\
\hline \multirow{3}{*}{$\begin{array}{c}\text { Daily } \\
\text { peak } \\
\text { averting }\end{array}$} & 1 & Close from 8:00 a.m. to 12:00 p.m. & & 3 & Wednesday close \\
\hline & 2 & Close from 13:00 a.m. to 17:00 p.m. & & 4 & Thursday close \\
\hline & 3 & Close from 18:00 a.m. to 22:00 p.m. & & 5 & Friday close \\
\hline
\end{tabular}

Correction Matrix. One large user is presumptively numbered as $\mathrm{n}$. The matrix form of its typical daily load curve is as follows:

$$
\eta_{n}=\left[\mu_{1}, \mu_{2}, \mathrm{~L}, \mu_{x}, \mathrm{~L}, \mu_{23}, \mu_{24}\right] \text {. }
$$

Where $\mu_{x}$ is the load value of this user at $x$ hour, since its participation in the orderly power utilization, the load change matrix of this user at $i$ day of the preplan week can be expressed as follows:

$$
\eta_{i, n}^{T}=f\left(\theta_{n}, \eta_{n}\right) \quad(i=1,2, \mathrm{~L}, 7) .
$$

Where $\theta_{n}$ is the control coefficient of the $n$ user as well as the input variable of decision-making model. Different $\theta_{n}$ values represent different orderly power utilization means, i.e. different load change matrix. The $n$ large user's security load is presumptively set as $I_{n}$.

When $1 \leq \theta_{n} \leq 6$, the means that the $n$ user participating in orderly power utilization is daily peak shifting.

When $\theta_{n}=1$, this user participates in grading 1 of daily peak shifting (put work time two hours ahead), and the load change matrix is generated as follows:

$$
\eta_{i, n}^{T}=\left[\mu_{3}-\mu_{1}, \mu_{4}-\mu_{2}, \mathrm{~L}, \mu_{24}-\mu_{22}, \mu_{1}-\mu_{23}, \mu_{2}-\mu_{24}\right](i=1,2, \mathrm{~L}, 5) .
$$

I.e. left shift the factor of user's daily curve matrix for two digits, and make a difference with original load matrix. When $\theta_{n}=2,3,4,5$ and 6 , the user correspondingly participates in grading 2- 6 of daily peak shifting; When $\theta_{n}=7$, the user participates in peak load shifting; When $\theta_{n}=8,9,10,11,12$ and 13 , the user participates in grading $1-6$ of weekly peak shifting; When $\theta_{n}=14,15,16$, the user participates in grading $1-3$ of daily peak averting; When $\theta_{n}=17,18,19,20$ and 21, the user participates in grading 1- 5 of weekly peak averting; And the load change matrix can be obtained on the same basis.

So, the load change matrix generated by orderly power utilization at $i$ day is as follow:

$$
\eta_{i}^{T}=\sum_{n=1}^{\operatorname{Max}} \eta_{i, n}^{T}(i=1,2, \mathrm{~L}, 7) \text {. }
$$


Where, Max is the total number of large users to participate in the orderly power utilization plan. The load correction matrix of preplan week can be expressed as follows:

$$
T_{7 \times 24}=\left[\begin{array}{lllllll}
\eta_{1}^{T} & \eta_{2}^{T} & \eta_{3}^{T} & \eta_{4}^{T} & \eta_{5}^{T} & \eta_{6}^{T} & \eta_{7}^{T}
\end{array}\right]^{T}
$$

Where, $T_{7 \times 24}$ is load correction matrix, i.e. the superposition of load change values generated by all large users' participation in the orderly power utilization.

Economic Cost. From the correction matric due to users' participation in the orderly power utilization plan, the economic cost function $Y$ can be expressed as follows:

$$
\begin{aligned}
& Y=\sum_{i=1}^{7} \sum_{n=1}^{\mathrm{Max}} C_{i, n}=\sum_{i=1}^{7} \sum_{n=1}^{\mathrm{Max}}\left(C_{i, n}^{p}-C_{i, n}^{v}\right) . \\
& C_{i, n}^{p}=\left(\frac{\left|\eta_{i, n}^{T}\right|-\eta_{i, n}^{T}}{2}\right) \cdot M_{n} . \\
& C_{i, n}^{v}=\left(\frac{\eta_{i, n}^{T}+\left|\eta_{i, n}^{T}\right|}{2}\right) \cdot M_{n} \quad M_{n}=\left[M_{1, n}, M_{2, n}, \ldots, M_{j, n}, \ldots, M_{23, n}, M_{24, n}\right]^{\mathrm{T}} .
\end{aligned}
$$

Where, $C_{i, n}$ is economic cost of the $n$ large user counted at $i$ day after its participation in the orderly power utilization. $C_{i, n}^{p}$ is reduction in total electric-selling amount of this user due to peak averting, and $C_{i, n}^{v}$ is increase in total electric-selling amount of this user due to valley filling. $M_{j, n}$ is electricity price of the $n$ large user at $j$ hour, see its value in literature [4].

\section{Simulation Example}

The simulation example is based on typical daily load curves of 54 large users, and weekly dimension forecast results in this region, and genetic algorithm is also chosen as optimization tool for the model simulation [5]. The upper limit of grid load ideal operating range is assumed 1.1 million $\mathrm{kW}$. In order to satisfy grid reliability [6], the electric quantity beyond the upper limit shall not exceed 100 thousand $\mathrm{kWh}$ per week. For study the relationship between the load gap and economic cost of power companies, diverse magnitude $\lambda$ values are selected for simulation. See simulation results in Table 2 below.

Table 2. Simulation results at diverse magnitude $\lambda$ value

\begin{tabular}{|c|c|c|}
\hline$\lambda$ & $Y($ Million Yuan $)$ & $X($ Thousand $\mathrm{kWh})$ \\
\hline 0 & 1.654 & 0 \\
\hline 0.1 & 0.667 & 0.48 \\
\hline 1 & 0.396 & 148 \\
\hline 10 & 0.201 & 2055 \\
\hline 100 & 0.052 & 2888 \\
\hline
\end{tabular}

From Table 2, on the basis of satisfying grid reliability, the $\lambda$ interval corresponding to the minimum economic cost of power companies is [0.1 1]. In order to further determine minimum economic cost point, the step of this model at diverse $\lambda$ values within [0.1 1 ] interval is set as 0.1 . See load gaps and economic cost's variation shown in Fig. 1 . It's shown that when the $\lambda$ value is selected as 0.9 , orderly power utilization plan reaches the minimum economic, while maintaining grid operation within reliable range. Compared with conventional solution $(\lambda=0)$, the economic cost of power companies has significantly reduced to 0.313 million Yuan from 1.654 million Yuan. It's seen that the optimization model can effectively reduce economic cost of power companies in carrying out orderly power utilization plan. 
The variation of means that users participate in the orderly power utilization at diverse $\lambda$ values in this proposed optimization model can be saw in Fig.2.

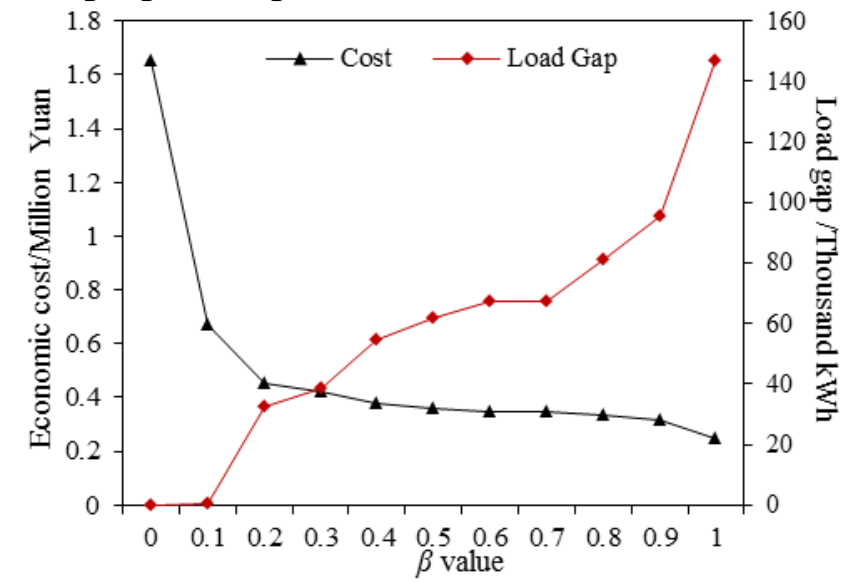

Fig.1. Variation of load gap and cost

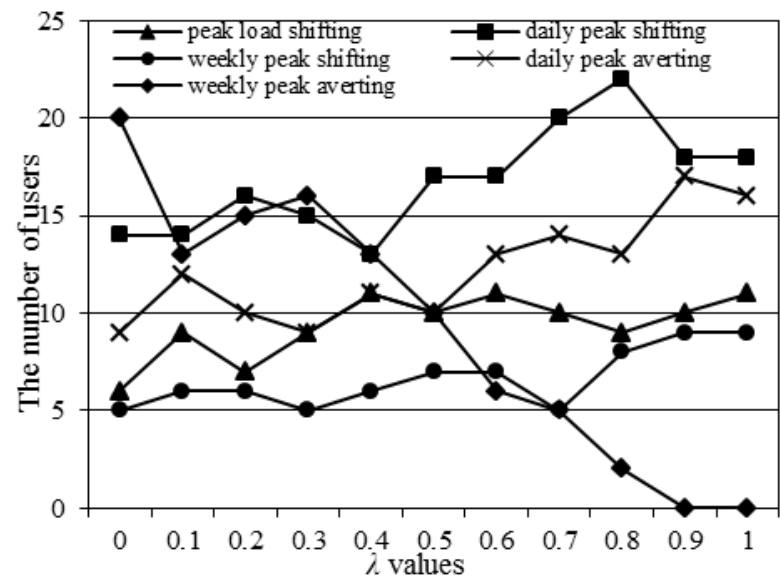

Fig.2. Variation of users' participation means

From Fig.2, the number of weekly peak averting users decreased gradually from 20 to 0 with the increasing of $\lambda$ value. Thus it's prudent to use the means of weekly peak averting, for its weak performance in economy compared to other means. In contrast, the number of users participating in other means increase in varying degrees. It's seen that the optimization process of the decision-making model lies in properly distributing users of weekly peak averting to other orderly power utilization means.

\section{Conclusion}

A decision-making mode of orderly power utilization based on users' typical daily load curves is proposed in this paper. The genetic algorithm is also chosen as optimization tool for the model applications. Simulation example shows that the orderly power optimization model constructed in this paper can effectively reduce economic cost of power companies in carrying out orderly power utilization, while satisfying grid reliability. Compared to the traditional way that the single capacity is used to denote user, the typical daily load curves selected in this mode can make plan more precise and accurate. This model will help decision-makers to choose the optimal orderly power utilization plan according to the actual situation in different region.

\section{References}

[1] Tingting Lu, Ciwei Gao, Weihua Su, Yang Li. Optimal schedule of peak load shifting by orderly power consumption management, J. Demand Side Management, 2013, 06:15-22.

[2] National Development and Reform Commission. Circular of the National Development and Reform Commission on the orderly power utilization management, R. Beijing: National Development and Reform Commission, 2011.

[3] Jia Wu, Kaijun Zhang, Jinyue Wang, Di Wu, Leijian Hu. Decision Support System for Orderly Power Utilization Based on Delicacy Management, J. ZHEJIANG ELECTRIC POWER, 2013, 04: 59-63.

[4] Zhejiang province's time sharing price list, EB/OL. 2014-06-13.

http://www.dongtou.gov.cn/zxfw/qyfw/ggsy/sdq/20140613/338858_1.htm

[5] Yingjie Lei, Shanwen Zhang. MATLAB genetic algorithm toolbox and application ,M. Second Edition. Xian: Xi'an Electronic and Science University press, 2014.

[6] Fei E etc. Overview of power system reliability, J. Electrical Engineering, 2006, 03: 5-8. 